\title{
Las heroicas y nobles acciones de la medicina
}

The heroic and noble actions of medicine

As ações heróicas e nobres da medicina

José Javier Elizalde González*

Heroico ha sido el comportamiento e inacabable trabajo desarrollado por el personal de salud durante el tiempo que ha durado esta pandemia, la peor crisis sanitaria de la humanidad en más de 100 años. Para dimensionar el significado de estos hechos, simplemente hay que recordar el sentido original de la palabra héroe, simbolizando a un semidiós o un jefe militar épico. En efecto, toda una epopeya ha sido el enfrentarse de manera valiente, organizada y decidida a este nuevo virus en el mundo; médicos, enfermeras, paramédicos, inhaloterapeutas, rehabilitadores, auxiliares, técnicos en muchas áreas, ingenieros biomédicos, personal de mantenimiento e intendencia, farmacia, seguridad, camilleros, voluntarios y personal de apoyo administrativo, todos al unísono haciendo equipo con un solo fin: atender de la mejor manera posible al enfermo grave con COVID-19, como usualmente se hace en el día a día del quehacer al interior de los hospitales y de las unidades de terapia intensiva; sin embargo, en esta ocasión ha sido distinto, todo ha transcurrido en una atmósfera diferente, con largas y desgastantes jornadas llenas de desasosiego y temor, con muchos casos de insuficiencia respiratoria aguda grave producida por un nuevo virus del que al principio muy poco se sabía, excepto su gran contagiosidad y potencial producción de complicaciones y muerte en cantidad nunca antes vista en la medicina moderna. La respuesta fue igualmente masiva, todas las especialidades se involucraron prácticamente en la atención médica de estos casos, acorde con las inmensas necesidades de atención sanitaria, la Medicina Interna, la Infectología, la Nefrología, la Neurología y la Cirugía, entre otras, pero particularmente las especialidades que por su naturaleza constituyen la primera línea de defensa, como la Medicina de Urgencias, la Neumología y la Medicina Crítica. Aun sin saberlo, un beneficio enorme ha recibido la sociedad de estos médicos, habitualmente muy jóvenes, quienes por más de un año han puesto con firme y encomiable compromiso todo su trabajo, empeño, conocimientos, habilidades y destrezas para salvar vidas o al menos intentar limitar el

\footnotetext{
* Head Pulmonary Service, Instituto Nacional de Ciencias Médicas y Nutrición Salvador Zubirán. UNAM. México.

Citar como: Elizalde GJJ. Las heroicas y nobles acciones de la medicina. Med Crit. 2021;35(4):170-171. https://dx.doi.org/10.35366/101153

www.medigraphic.com/medicinacritica
}

daño dentro de un sombrío ambiente de incertidumbre, improvisación, precariedad y en algunos casos falta de guía, liderazgo y de recursos en general.

Sin embargo, no es la primera vez que queda manifiesta la heroicidad del quehacer médico, muchos ejemplos existen en la historia de México del enorme empeño del personal de salud que ha alcanzado en más de una ocasión niveles de histórico sacrificio, siguiendo el tradicional espíritu de servicio de la medicina para con la sociedad; es así que podemos señalar unos cuantos ejemplos.

Virtualmente, al mismo tiempo que la epidemia de la viruela arrasaba México a finales del siglo XVIII, Edward Jenner desarrollaba su nuevo método de implantación artificial del virus activo de esta enfermedad para crear una vacuna, lo que rápidamente se extendió por Europa. Corría el inicio del siglo XIX cuando el Rey Carlos IV ordenó organizar una expedición para difundir la vacuna a lo largo de todo su imperio, por lo que comisionó a Francisco Xavier Balmis, su médico, como responsable de la Real Expedición Filantrópica de la Vacuna, que partió de la Coruña el 30 de noviembre de 1803 con rumbo a las colonias americanas, junto con un valiente grupo de médicos españoles, acompañados de la enfermera Isabel Zendal, rectora del orfanato de la caridad de la Coruña, constituyendo así la primera cruzada internacional de vacunación. Esta expedición, aunque bajo la dirección de Balmis, cirujano honorario de cámara, fue igualmente encargada a otros muchos médicos miembros de la Facultad, para observar la marcha y progresos irregulares que pudieran ocurrir en la vacuna, por las variedades atmosféricas de los diversos climas que iban a tocar en tan largo periplo, como de cirujanos para practicar la vacunación, llevando a bordo 22 niños que no habían padecido la viruela para inocularlos, uno después de otro, durante la navegación, y tener el fluido vacuno fresco para comunicarlo de uno en uno. Cuál sería la sorpresa de Balmis al enterarse a su llegada a México en 1804, que la vacuna había llegado antes que él. En efecto, un año antes, el virrey José de Iturrigaray la había traído en su equipaje, haciendo que su médico personal, Alejandro Arboleya, realizara una vacunación siendo testigos miembros del Real Protomedicato, y el Dr. Antonio Serrano, director de la Real Escuela de Cirugía. Desgraciadamente, por el desconocimiento técnico y el largo viaje de España a América, el producto no tenía ya actividad alguna, llegando, no obstante, poco 
tiempo después nuevas vacunas al puerto de Veracruz en la fragata Anfitrite y $\mathrm{O}$, con lo que se procedió a vacunar a cinco huérfanos y al hijo del propio Virrey. Esto no resta honor a Balmis, quien se enfocó en preservar y estabilizar la producción de la vacuna y debe ser recordado junto con su equipo por sus heroicos actos que, con toda seguridad, salvaron la vida de millones.

Medio siglo después, cuando corría el año 1859, México se encontraba envuelto en una guerra fratricida, la Guerra de Reforma. El 11 de abril de ese año el combate llegó hasta el actual rumbo de Tacubaya, al poniente de la Ciudad de México, donde tanto militares como civiles agonizaban en las calles, cuando un grupo de voluntarios médicos y estudiantes de medicina se organizaron para prestar sus servicios. Al enterarse de ello, el polémico, sanguinario e inhumano jefe militar vencedor bautizado por la gente como el Tigre de Tacubaya y el Carnicero de Tacubaya, el conservador general Leonardo Márquez, quien apoyaba la Intervención Francesa, ordenó fusilar a los jefes y oficiales liberales capturados en la derrota, entre ellos al jefe del cuerpo médico militar, junto con los médicos y estudiantes de medicina que asistían a los heridos, personal de salud conocido desde entonces como los «mártires de Tacubaya», muchos de ellos anónimos al paso del tiempo, aunque varios de los nombres de esos héroes médicos que murieron intentando salvar vidas se lograron conservar, como hace alusión la placa conmemorativa de dichos hechos promovida por el Bloque Nacional de Médicos y que se encuentra desde el 11 de abril de 1955 en ese lugar, ellos son los Doctores Juan Díaz Covarrubias, Francisco Portugal, Alberto Abad, Gonzalo Rivera y José Ma Sánchez, entre otros.

A inicios del siglo pasado, estudiantes de la entonces Escuela Nacional de Medicina, hoy Facultad de Medicina de la UNAM, ante la enorme mortandad de la pandemia de la mal llamada «gripa española» que flageló a la humanidad en 1918, con escasísimos recursos (quinina, ácido acetilsalicílico y carbonato de calcio), con mucho coraje y valentía partieron a distintos puntos de la República Mexicana a cubrir las plazas de trabajo vacantes por carencia, muerte de los galenos locales o inactividad voluntaria de los médicos de la región ante el temor de ser contagiados de influenza, ésas constituyeron verdaderas jornadas heroicas de enorme repercusión social, lo que queda patente con setenta generaciones de estudiantes de medicina que a nivel nacional han mantenido vivo con su trabajo al sistema de salud de la nación, al brindar sin retribución alguna 12 meses de arduo trabajo social en medicina en todas las poblaciones del país que lo requieren, a pesar de las adversas condiciones de trabajo que esto representa y en la actualidad el riesgo hacia su integridad y seguridad personal.

Hasta llegar a los médicos residentes actuales, particularmente los de Terapia Intensiva, lo mismo que las enfermeras intensivistas, inhaloterapeutas y todo el personal que entra físicamente al área COVID-19 y permanece diariamente turnos enteros ahí brindando sus servicios y exponiendo su propia integridad física, ellos son los verdaderos héroes en esta pandemia, ya que además de haber salvado vidas, aportado cuidados médicos y acompañamiento a los pacientes en necesidad de ello, han salvaguardado tal vez sin darse cuenta el buen nombre de las instituciones, y sostenido y apoyado al sistema de salud. Esto sin condiciones ni temor, de manera natural y con la frescura que sólo la juventud puede dar, con energía, cumplimiento y entereza a pesar de la adversidad y todas las fallas de los sistemas de salud a lo largo de la epidemia.

Es necesario el reconocimiento amplio y sincero a estas jóvenes generaciones de médicos y enfermeras intensivistas, inhaloterapeutas y resto de personal sanitario que vive en y para la Terapia Intensiva por los heroicos servicios prestados a la sociedad durante estos tiempos de pandemia; ellos representan lo mejor que la medicina puede brindar y constituyen claramente su presente y futuro, ellos son los verdaderos héroes de la pandemia.

Correspondencia:

Dr. José Javier Elizalde González

E-mail: jjeg@unam.mx 